\title{
Alfabetizando e desenvolvendo competências linguísticas a partir do conto de estórias
}

\begin{abstract}
Resumo: O presente artigo propõe a utilização didática do conto de estórias em classes de Educação Infantil e do Ensino Fundamental, objetivando a promoção dos processos de alfabetização e letramento de modo lúdico e motivante. O ato de ler, contar e ouvir estórias contribui para o desenvolvimento do "pensamento narrativo", que, segundo Bruner (1986), ocupa-se das intenções e das ações humanas e dos resultados gerados pelas mesmas. Tal modalidade de pensamento ajuda a criança a compartilhar, interpretar e compreender melhor os eventos quotidianos do mundo circunstante. Muitos estudos comprovaram os benefícios da utilização didática e educativa do conto de estórias e/ou da narração autobiográfica em vários âmbitos do desenvolvimento e da aprendizagem infantil, tais como a ampliação do léxico, a aquisição de competências linguísticas e metalinguísticas, o desenvolvimento de comportamentos alfabetizados e meta-alfabetizados, além de favorecer também o desenvolvimento psíquico e emocional da criança.

Palavras-chave: Arte de contar histórias. Alfabetização.
\end{abstract}

O "conto de estórias", conhecido internacionalmente como story telling, é uma das possibilidades mais interessantes para familiarizar crianças pequenas com o universo da língua escrita. O livro de estórias, além de representar um produto cultural historicamente legitimado, representa um objeto "mágico" a ser explorado, que envolve não só a dimensão cognitiva mas também aquela das emoções.

O ato de ler, ouvir e/ ou de contar uma estória é capaz de ativar uma específica modalidade de pensamento: o pensamento narrativo. Segundo Bruner (1986), é provável que esta forma de pensamento coexista com o pensamento lógico-científico no interior das estruturas mentais, exercendo porém uma função diferente: ocupa-se das intenções e das ações humanas e dos resultados gerados pelas mesmas. Dessa forma, o pensamento narrativo é intrinsecamente vinculado a uma dimensão subjetiva e emotiva, e emerge em todas as situações onde o sujeito busca compreender, de modo simbólico, a realidade que o circunda. O conto, seja este oral ou escrito, seria então um produto cultural fruto dessa modalidade de pensamento, sendo portanto presente desde sempre na vida dos indivíduos de qualquer tempo e cultura; pois, para fazer parte de uma coletividade, cada sujeito deve antes
Ana Rita de Cássia Santos Barbosa Pedagoga 
de tudo adquirir e partilhar o sistema simbólico do seu contexto sociocultural. (GROPPO, et al., 1999)

As interações linguísticas realizadas com o adulto, através do conto, pode fornecer à criança a oportunidade de apropriar-se rapidamente de uma competência narrativa. Tal competência ajuda a criança a interpretar, compartilhar e compreender melhor os eventos quotidianos. Com o passar do tempo, ela poderá tornarse um construtor ativo de tal realidade social. O decorrer do desenvolvimento dessa competência é marcado por três formas graduais de conhecimento, segundo Bruner (1996): a primeira, a inter-subjective mode, refere-se a intersubjetividade, que se desenvolve já nos primeiros anos de vida da criança através das interações que se dão entre mãe e filho; a segunda, a action mode, refere-se aos argumentos correspondentes às ações: o que se faz, com qual objetivo e com quais instrumentos; e a terceira, a normative mode, refere-se à construção de significados e normas que regulamentam o comportamento dos indivíduos. Tais formas de conhecimento são presentes em modo coerente na estrutura de um conto narrativo, legitimando, pois, a narração de estórias como um dos percursores para o desenvolvimento da competência narrativa das crianças.

Além de favorecer o desenvolvimento da competência narrativa, a prática de contar estórias envolve três principais áreas que favorecem os processos de alfabetização e letramento: as habilidades metacognitivas, a consciência metalinguística e o desenvolvimento de comportamentos alfabetizados e metaalfabetizados. (BRICE-HEATH; THOMAS, 1984; SAPHIRO, 1996; SHAPIRO; HUDSON, 1996) As primeiras habilidades acima citadas referem-se ao saber explicar, descrever, atribuir nomes e utilizar "verbos cognitivos" como "penso", "acho", "imagino", etc. A consciência metalinguística revela-se na capacidade de refletir acerca da linguagem e sobre os seus elementos, como por exemplo, refletir sobre as funções sociais da língua escrita, os seus diversos contextos de utilização, conhecer e refletir sobre as suas várias formas e elementos (formas gráficas diversificadas, aspectos fonológicos, atribuição de significados), analisar uma palavra também fora do contexto no qual a mesma aparece, etc. Os comportamentos alfabetizados e meta-alfabetizados referem-se, por sua vez, ao desenvolvimento de posturas e atitudes que revelam conhecimentos sobre os objetos culturais da escrita (saber

28 R. Faced, Salvador, n.14, p.27-37, jul./dez. 2008 
como posicionar um livro, conhecer a direção "esqueda-direita" para a realização de uma leitura, saber como as páginas de um livro devem ser giradas, etc), e o desenvolvimento de um pensamento crítico (a capacidade de análise, de reflexão, o ato de perguntar, a solicitação de explicações, etc). (DE BENI; CISOTTO; CARRETTI, 2002)

Estudos desenvolvidos por Bellone e Ogletree (2004) confirmam as informações descritas. Tais estudos revelam a existência de "elementos-chaves" do conto de estórias, que favorecem o processo de alfabetização: a redundância, a complexidade semântica e a estrutura narrativa. A redundância consiste na leitura repetida de uma mesma estória com o objetivo de explorar diversos aspectos do texto, como as variações linguísticas de acordo com as ações e os eventos da estória, a ortografia, o significado, etc. A complexidade semântica está na natureza concreta ou abstrata dos significados existentes na linguagem utilizada e é caracterizada por seis níveis hierárquicos de evolução nas crianças. Tais níveis são a indicação: o gesto indicativo e a expressão não verbal; a designação: quando a criança começa a utilizar palavras que se referem a pessoas ou objetos concretos; a descrição: iniciam a descrever as características dos objetos ou das ações; a interpretação: o discurso comunicado não é algo que pode ser observado diretamente, como ocorria na fase de descrição, mas é consequência da interpretação de imagens, estados, mudanças, etc; a inferência: o significado ultrapassa aquilo que vem sugerido pelo seu conteúdo; a metalinguagem: representa o nível mais alto da capacidade de abstração, através do qual as crianças podem expressar seus conhecimentos acerca das características da linguagem. Enfim, a estrutura narrativa caracteriza-se pela sistematicidade das regras presentes no texto, conhecidas também como "gramática do conto". Tal "gramática" é composta de elementos linguísticos e estruturais, típicos de toda estória, como por exemplo: as personagens (a protagonista e a antagonista), a apresentação inicial da estória, a sucessão de eventos e ações complexas, o final. As fábulas, por exemplo, possuem características morfológicas comuns que possibilitam a análise das mesmas, pois vêm definidas como qualquer evento que se desenvolve a partir de uma ruptura ou de uma perda e que, através de funções intermediárias, alcança uma ação conclusiva. (PROPP, 1928) A descoberta de tais regularidades facilitaria a compreensão textual e 
a criação de estórias por parte da criança, contribuindo também para um melhor desenvolvimento das habilidades linguísticas, em nível oral e escrito. Bellone e Ogletree (2004) afirmam que a utilização do conto de estórias nas atividades didáticas pode favorecer a superação de deficiências linguísticas e de dificuldades de leitura, visto que o conto representaria uma oportunidade para desenvolver contemporaneamente uma série de habilidades e competências: reconhecimento de letras, relações entre o som e o símbolo, conhecimentos sobre a construção de um texto, conhecimentos sintáticos, semânticos e ampliação do léxico.

Muitos são os estudiosos que comprovaram os benefícios do conto de estórias para o desenvolvimento dos processos de alfabetização. Ainda mais relevante e urgente para a realidade social brasileira, seria adotar tais práticas didático-educativas com as crianças das classes populares, que possuem poucas oportunidades de interagir com livros e material escrito. Um estudo realizado com 400 crianças de três e quatro anos, provenientes de classes populares nos Estados Unidos, analisou os efeitos de uma intervenção educacional que forneceu às mesmas a possibilidade de obter contato com livros e realizar interações verbais acerca da lecto-escrita. Aquelas que obtiveram tal oportunidade desenvolveram competências linguísticas e conhecimentos acerca da língua escrita significativamente superiores às competências desenvolvidas pelas crianças do grupo de controle. (NEUMAN, 1999) Uma pesquisa longitudinal constatou que as competências linguísticas e narrativas adquiridas pelas crianças em idade "pré-escolar" tornam-se fundamentais nas fases sucessivas de alfabetização, ou melhor, nas fases de letramento. (PINTO; BIGOZZI, 2002) Segundo as autoras, as crianças que na idade de cinco anos eram capazes de contar oralmente uma estória em modo coerente, foram aquelas posteriormente mais bem-sucedidas na capacidade de produção de textos.

Além de contribuir para o desenvolvimento de competências linguísticas e metalinguísticas, o conto de estórias pode favorecer também o desenvolvimento psíquico e emocional da criança, que enquanto cresce é sempre em busca da própria identidade, apoiando-se nos modelos que encontra. Segundo Bruner (1996), a escola possui uma grande responsabilidade social em tal processo, pois um sistema educativo deve ajudar quem cresce 
em uma determinada cultura a encontrar a própria identidade, a dar um significado à própria existência. As narrativas, sejam estas orais, escritas, ou até autobiográficas, dão ao sujeito a possibilidade de construir uma identidade e de encontrar-se dentro da própria cultura. As escolas, portanto, deveriam promover o desenvolvimento de tal competência. Refletindo acerca de tal aspecto é natural pensar na promoção e divulgação de contos orais e escritos e de livros infantis que retratem a realidade pluricultural brasileira, resgatando, por exemplo, estórias e lendas típicas da tradição oral africana e indígena, favorecendo assim o processo de construção da identidade das crianças. Há séculos, esse processo vem sendo negado através da legitimação apenas de contos de origem europeia, enquanto a abordagem de outros povos e culturas é ainda "tímida" ou limitada, e em muitos casos é feita em modo superficial e distorcido, através da "folclorização" e da promoção de estereótipos.

Experiências e atividades educativas baseadas no conto ou na criação de estórias, ou ainda no relato autobiográfico, são frequentemente utilizadas como percursos alternativos e/ou de reabilitação de crianças com dificuldades de aprendizagem, com problemas emotivos ou com patologias específicas. Segundo Hagood (1997), o hábito de analisar e discutir a estrutura de um conto facilita a compreensão de um texto, ajudando portanto o aluno com dificuldades a desenvolver habilidades de reflexão crítica. Bauer e Balius (1996) sugerem a utilização da narração de estórias para ajudar crianças com problemas emocionais a reforçarem a própria autoestima, ativando contemporaneamente conhecimentos e competências no âmbito linguístico e metalinguístico. Para os autores mencionados, os alunos podem vivenciar um "deslocamento afetivo", identificando-se com os personagens da estória e "dividindo" com estes as próprias emoções. Adquire-se então uma maior consciência acerca dos próprios sentimentos e emoções e como esses possam influenciar um determinado comportamento. Já as experiências conduzidas por Cusan e Campagnolo (2003) constituem-se um exemplo de uso do conto de estórias e do relato autobiográfico na reabilitação de crianças com patologias específicas. As estudiosas realizaram oficinas, que foram propostas e construídas juntamente com as crianças, e evidenciaram alguns progressos como a ampliação do vocabulário, o desenvolvimento de habilidades morfológicas e 
da capacidade de fazer inferências. No final da experiência as estudiosas constataram o papel crucial da motivação para estimular a aprendizagem.

A utilização didática do conto de estórias durante as fases de alfabetização pode ser algo muito motivante e enriquecedor para os alunos. Bellone e Olgletree (2004) trazem algumas sugestões didáticas para uma melhor utilização dos textos narrativos para o ensino/aprendizagem da língua escrita: observar os conteúdos da estória; a estrutura narrativa deve ser previsível para a criança; a linguagem deve ser acessível; verificar a presença de imagens concretas nas ilustrações e a possibilidade de explorá-las posteriormente com jogos e atividades lúdicas. Não são considerados adequados livros descritivos ou com estórias muito longas e complexas. Após o conto da estória, é possível realizar muitas atividades que terão a vantagem de estar "ancoradas" em um contexto significativo, favorecendo a motivação à aprendizagem. Dessa forma, a aprendizagem da língua escrita é sustentada pelos significados encontrados em cada narração, pelos sentimentos e emoções evocados, pelas personagens preferidas. Cada palavra, portanto, não é uma "palavra qualquer", mas representa uma "ponte" entre a imagem mental da criança, evocada pela estória, e o signo abstrato (o código alfabético) que a representa.

Estudos realizados com pacientes adultos no âmbito da neuropsicologia cognitiva propõem a existência de duas rotas, ou estratégias de leitura que podem ser utilizadas de acordo com as necessidades do leitor e das características do sistema linguístico. (HARRIS; COLTHEART,1986) A rota lexical baseia-se no acesso direto ao léxico mental quando se reconhece uma palavra global e rapidamente. Essa é a rota mais utilizada pelos leitores experientes, que já possuem um amplo repertório lexical registrado na própria mente. Tal repertório vem ativado toda vez que se realiza uma leitura, exercitando portanto o reconhecimento global e imediato das palavras. A outra rota, conhecida como indireta, e que é geralmente aquela utilizada pelos leitores principiantes, é a rota fonológica. Neste caso a palavra não é lida de modo automático, mas o leitor necessita da conversão grafemafonema. Palavras desconhecidas podem ser lidas apenas pela rota fonológica, enquanto as palavras mais frequentes podem ser lidas rapidamente através da rota lexical. Em relação à língua 
portuguesa, cuja ortografia é considerada "não transparente", pois não existe uma relação biunívoca fonema/grafema na escrita ortográfica de muitas palavras (um grafema pode representar mais de um fonema e/ou um fonema pode ser representado por mais de um grafema. Ex: casa e sal; exato e experiência, etc), o leitor deve desde cedo "habituar-se" a utilizar a rota direta, lexical, para realizar uma leitura correta das palavras. A reflexão acerca de tal modelo pode trazer interessantes contribuições para uma didática da alfabetização ancorada em experiências significativas, como o conto de estórias. Os conhecimentos semânticos e a ampliação do repertório lexical poderiam facilitar o desenvolvimento dos processos de aquisição da lecto-escrita.

Cisotto (2006), apoiando-se no modelo acima descrito, propõe a existência de uma didática que possa integrar a Educação Infantil ao Ensino Fundamental, através do conto de estórias. As experiências precoces no âmbito narrativo constituem-se uma oportunidade não só de conhecer tal gênero textual, mas também de compreender os elementos que o caracterizam, como a coesão, a coerência e a conexão semântica, além de contribuir para a ampliação do léxico. Tem-se as seguintes sugestões de atividades ou percursos que podem ser propostos para este fim: jogos metalinguísticos, ou seja, de reflexão sobre a língua, que estejam contextualizados na estória lida ou contada; atividades de animação à leitura (antes e depois do conto da estória), para favorecer a motivação, mas também para desenvolver alguns aspectos (a consciência fonológica ou a compreensão textual, por exemplo) e para dar aos alunos a possibilidade de fazer inferências sobre a estória; conversações após o conto; reprodução pictórica dos cenários, personagens e reconto da estória por parte dos alunos; representações de elementos da estória (personagens e objetos concretos) através de imagens evocativas (simbolismo de primeiro grau), como, por exemplo, a retratação de elementos que lembram uma determinada personagem ( a boca aberta com os dentes do lobo é a representação simbólica da personagem "lobo"); e posterior representação dos mesmos elementos através de palavras (simbolismo de segundo grau). As duas últimas atividades citadas favorecem os processos de evolução simbólica da língua escrita. 
(1) As representações simbólicas podem ser feitas através de um desenho, ou de uma forma mais concreta, que pode ser construída com materiais simples, como papelão ou cartolina, de modo que possa ser manuseada pela criança.

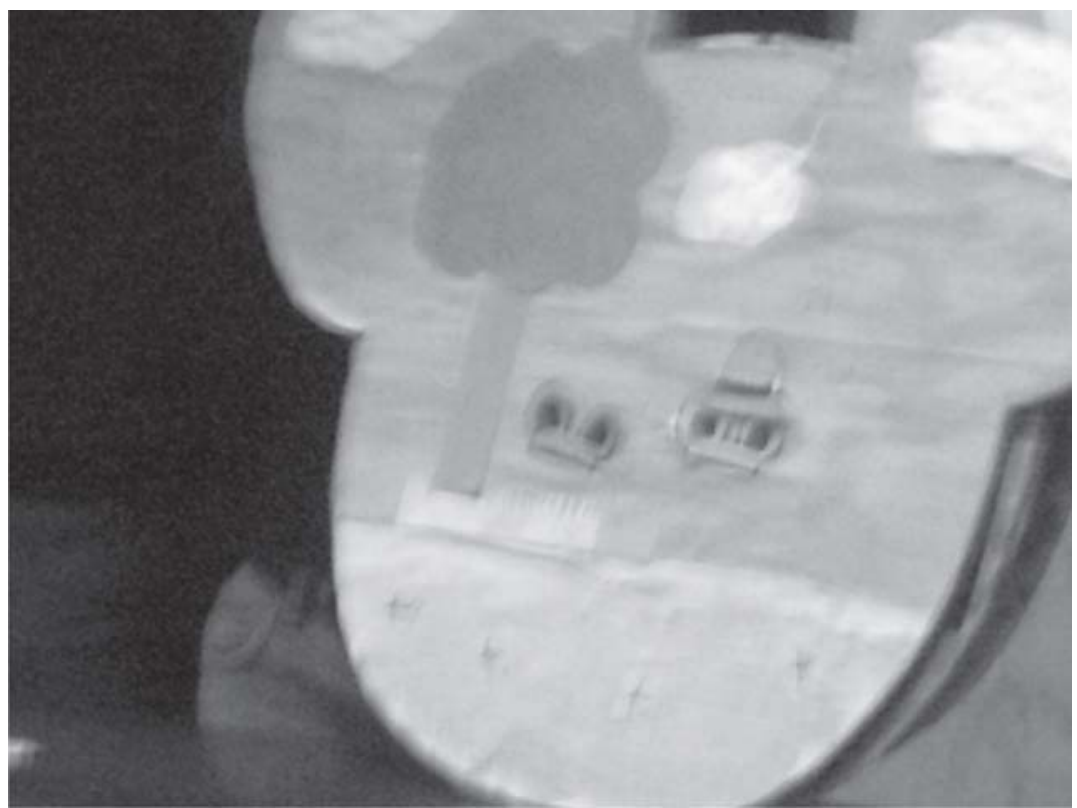

Figura 1 - Exemplo de representaçōes simbólicas das personagens (simbolismo de primeiro grau): as orelhas das personagens "rato do campo" e "rato da cidade".

Ao procurar identificar objetos e personagens da estória nas imagens-símbolos correspondentes, os alunos desenvolveriam a primeira fase, chamada de simbolismo de primeiro grau. Tais imagens simbólicas poderiam ser produzidas pelo professor ou pelos próprios alunos. No caso de crianças muito pequenas (três ou quatro anos), tal processo poderia ser desenvolvido gradualmente. As representações ${ }^{1}$ "fiéis" das personagens, em uma fase inicial, transformar-se-iam gradativamente em formas cada vez mais abstratas, dando lugar às representações simbólicas das mesmas. Sendo assim, em atividades iniciais, a criança reconheceria, por exemplo, a personagem "rato" através de uma retratação pictórica e/ou concreta mais ou menos "fiel"; e em atividades sucessivas ela reconheceria a representação simbólica da mesma personagem, que deveria ser algo evocativo mas simultaneamente de fácil reconhecimento (ex: o focinho, o rabo, as orelhas, um objeto ou indumento utilizado, etc). Posteriormente, as crianças poderiam "brincar" de tentar reconhecer as palavras que representam tais personagens (leitura inventada) e/ou de tentar escrevê-las (não se trataria de uma cópia mas de uma tentativa de escrita espontânea),

34 R. Faced, Salvador, n.14, p.27-37, jul./dez. 2008 
entrando assim na fase de simbolismo de segundo grau. O percurso descrito pode ser também utilizado para alfabetizar crianças do Ensino Fundamental. Em tal caso seria preciso ir além da "brincadeira" de tentar ler e escrever, aprofundando aspectos gráficos, fonológicos, ortográficos e semânticos da língua, e desenvolvendo o potencial metacognitivo do aluno, através de atividades que estimulassem uma contínua reflexão acerca das semelhanças e diferenças entre a escrita inventada e aquela convencional. Nesta segunda fase, as duas rotas do modelo anteriormente descrito (a rota lexical e a rota fonológica) vêm ativadas contemporaneamente possibilitando à criança uma melhor compreensão do mecanismo alfabético de funcionamento da língua escrita, pois a "palavra-modelo" que ela consegue identificar automaticamente (o nome da personagem de uma estória, por exemplo), contrasta com a sua tentativa de escrita espontânea. Ta1 contraste provoca conflitos cognitivos que possibilitam ao aluno refletir e avançar na sua hipótese de representação da língua escrita. ${ }^{2}$

Conclui-se, portanto, que a utilização do conto de estória nas atividades didáticas e educativas pode trazer inúmeros benefícios em vários âmbitos do desenvolvimento e da aprendizagem infantil. Tais atividades podem ser de familiarização com a língua escrita (no caso de crianças pequenas), ou de estudo sistemático dos elementos que a compõem, a fim de favorecer o desenvolvimento de habilidades linguísticas e metalinguísticas, essenciais à evolução dos processos de alfabetização e de letramento. O contexto significativo e motivante criado através do conto de estórias caracteriza-se como uma importante "base de apoio" para analisar aspectos fonológicos, ortográficos e morfológicos da língua. Além disso, as competências narrativas adquiridas pelas crianças constituem-se importantes "ferramentas" que possibilitarão às mesmas, em um segundo momento, um melhor desenvolvimento da capacidade de produzir e compreender textos escritos. Oferecer tais oportunidades didático-educativas às crianças significa dar às mesmas os instrumentos necessários para que possam desenvolver as próprias potencialidades no âmbito da língua escrita e da oralidade, além de cultivar o prazer pela leitura.

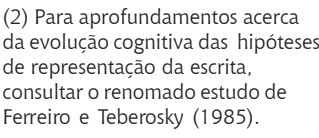




\section{Literating and developing linguistic skills through storytelling}

Abstract: The current paper proposes the use of storytelling for didactic purposes in classes of Early Childhood Education and Elementary School, in order to promote literacy processes in a playful and motivating way. The act of reading, telling and listening to stories contributes to the development of the "narrative thinking" which, according to Bruner (1986), deals with human intentions and actions and with the results generated by them. Such a way of thinking helps the child to share, interpret and understand better each daily event coming from the surrounding world. Many studies prove the benefits of using storytelling and/or autobiographical narrative for didactic and educational purposes in various fields of child development and learning, such as lexical broadening, acquisition of linguistic and meta-linguistic skills, development of literate and meta-literate behaviours; moreover, it promotes the children's psychical and emotional development.

Keywords: Storytelling. Literacy.

\section{Referências}

BAUER, Martha S.; BALIUS JR, Fred A. Narrazione di storie: come integrare il sostegno psicologico e didattico Difficoltà di apprendimento, v. 2, n. 1, p. 29-36, 1996.

BELLONE, M.; OGLETREE, B.T. Usare i libri di fiabe e racconti per l'avviamento alla letto-scrittura. Difficoltà di apprendimento, v. 9, n. 4, p. 521- 530, 2004.

BRICE-HEATH, S.; THOMAS, C. The achievement of preschool literacy for mother and child. London: Heinemann Educational Books, 1984.

BRUNER, Jeromer. Actual minds, possible worlds. Cambridge (Mass.): Harvard University Press, 1986.

The culture of education. Cambridge (Mass.): Harvard University Press, 1996.

CISOTTO, Lerida. Didattica del testo: processi e competenze. Roma: Carocci, 2006.

CUSAN, D.; CAMPAGNOLO, A. Il laboratorio del pensare: strategie per insegnare l'organizzazione del racconto. Difficoltà di apprendimento, v. 9, n.1, p.95-108, 2003.

DE BENI, Rossana; CISOTTO, Lerida; CARETTI, Barbara. Psicologia della lettura e della scrittura. Trento: Erickson, 2002.

FERREIRO, Emilia; TEBEROSKY, Ana. Psicogênese da língua escrita. Porto Alegre: Artes Médicas, 1985.

GROPPO, M., et al. La psicologia culturale di Bruner: aspetti teorici ed empirici. Milano: Raffaello Cortina Editore, 1999.

HAGOOD, Barbara. F. Struttura del racconto e mappe narrative nella comprensione e produzione del testo. Difficoltà di apprendimento, v. 3, n. 4, p. 475- 482, 1997. 
HARRIS, M.; COLTHEART, M. Language processing in children and adults. London: Routledge e Kegan Paul, 1986.

NEUMAN, Susan B. Books make a difference: a study of access to literacy. Reading Research Quarterly, v. 34, p. 286-311, july/aug./ sep., 1999

PINTO, Giuliana; BIGOZZI, Lucia (Org.). Laboratorio di lettura e scrittura. Trento: Erikson, 2002.

PROPP, Vladimir. Morfologija skazki. Leningrad: "Accademia", 1928.

SAPHIRO, J. Home literacy environment and metaliterate aAwareness. In: REEDER, K. et. al. (Ed.). Literate apprenticeships: the emergence of Language and Literacy in the preschool years. New York: Ablex Publisching, 1996. p. 29-52.

SHAPIRO, L.R.; HUDSON, J.A. Coherence and cohesion in children's stories. In COSTERMANS, J.; FAYOL, M. (Ed.). Processing interclausal relationships: studies in the production and comprehension of text. Mahwah, NJ.: Erlbaum, 1996. p. 23-48. 